\title{
Development of novel mathematical models for laboratory studies of hydrolyzed polyacrylamide polymer injectivity in high-permeability conduits
}

\author{
Sherif Fakher ${ }^{1}[0$
}

Received: 29 November 2019 / Accepted: 17 February 2020 / Published online: 22 February 2020

(c) The Author(s) 2020

\begin{abstract}
Hydrolyzed polyacrylamide polymer (HPAM) is the most used polymer in enhanced oil recovery operations in the oil industry. This is mainly attributed to its cost and availability. An important aspect during polymer injection in the formation for mobility control is the ability to inject the polymer easily and safely in the reservoir without having to deal with extremely high pressure gradients and without risking formation fracture. This research develops two mathematical models that can help obtain values for polymer injectivity as a function of HPAM concentration, injection flowrate, and the porous media pore size. The mathematical models were developed based on experiments conducted previously using different polymer concentrations, pore sizes, and polymer injection flowrates. After the models were developed, different data were used to validate the model and examine its accuracy in determining polymer injectivity. The models were also used to predict polymer injectivity for different conditions and illustrate the pore sizes at which the polymer was not able to propagate in the formation. Since the models have several limitations, these were mentioned in the manuscript in order to reduce any error obtained while using the models.
\end{abstract}

Keywords HPAM $\cdot$ Injectivity $\cdot$ Mathematical models

\section{List of symbols}

$I_{\mathrm{p}} \quad$ Polymer injectivity

$Q \quad$ Polymer injection flowrate

$\Delta P \quad$ Difference between polymer injection and outlet pressures

$a \quad$ Fitting constant

$b \quad$ Fitting constant

$C_{\mathrm{p}} \quad$ Polymer concentration

$T_{\mathrm{s}} \quad$ Average porous media pore size

\section{Introduction}

Polymer flooding is an EOR method used mainly for mobility control. It can be coupled with multiple EOR methods for several improvements (Fakher and Imqam 2018, 2020a, b). Some of these methods can include other chemical methods

Sherif Fakher

smfb96@mst.edu

1 Missouri University of Science and Technology, Rolla, MO 65409, USA or solvent injection (Fakher et al. 2018; Fakher 2019a, b). The polymer solution will have a high viscosity and thus will overcome several displacement and mobility problems associated with water flooding, mainly viscous fingering (Zhou et al. 2019; Seright et al. 2018; Seright 2017). Different types of polymers have been developed and used to improve oil recovery and mobility control; however, HPAM polymer still remains the most widely used polymer for chemical EOR applications mainly due to its cost, availability, and ease of handling (Seright 2017; Koh et al. 2018; Fletcher et al. 1992; Buell et al. 1990; Gerlach et al. 2019).

Polymers are usually injected as a weight percent mixed with water (Erincik et al. 2018; Delamaide et al. 2014). As the concentration of the polymer increases in the solution, the cost of the polymer injection project increases, but also the polymer solution viscosity will increase (Smith 1970; Skauge et al. 2016; Bryant et al. 1998; Juri et al. 2015). This may be advantageous for mobility control; however, one of the overlooked parameters that will also be impacted is polymer injectivity (Baijal 1975; Glasbergen et al. 2015; Southwick and Manke 1988). Polymer injectivity can be defined as the ease by which the polymer can be injected into the formation (Shuler et al. 1987). If the polymer solution is too 
viscous, it may be extremely difficult, or sometimes impossible, to inject it into the formation (Seright et al. 2018). Injectivity is therefore an extremely important factor to consider when designing any polymer flooding project since it has a direct impact on cost of the overall project and can impact safety as well if the formation is fractured during injection (Sharma et al. 2016; De Simoni et al. 2018).

Many factors will affect polymer injectivity, including polymer concentration, polymer injection flowrate, and porous media pore size (Weiss and Baldwin 1985; Manichand et al. 2013; Li and Delshad 2014; Lotfollahi et al. 2016). Increasing the flowrate by which the polymer is injected, for the same pore size, will increase injectivity, but will also increase the pressure requirement and thus the pump power on the surface facility. The pore size of the formation will permit the flow of the polymer through it as long as the injection pressure is high enough, although if the polymer molecule is too large, the polymer may plug the pore. High-permeability media are used to refer to several porous media types depending on the application. For conventional reservoirs, it usually refers to permeability above $100 \mathrm{mD}$. This can include porous media, unconsolidated sand, natural fractures, and continuous fractures. Low permeability will refer to permeability less than $20-10 \mathrm{mD}$ based on the application. This, however, is sometimes impractical or impossible especially if the pore size is too small or the polymer solution is too viscous. Seright et al. (2009) researched three properties of polymers that may impact their injectivity, including polymer rheology in porous media, where they found that pseudo-plastic behavior for HPAM may occur if the pore structure is too small for the polymer to propagate through easily.

Several models have been developed to model polymers in the porous media. Delamaide (2019) showed that analytical methods can be used to accurately model polymer injectivity in many cases. Although the case studies presented in their study show a high-accuracy solution, the analytical solution applicability is questionable due to its high dependency on reservoir simulation tools which includes many assumptions. Schmidt et al. (2019) developed a model for predicting polymer injectivity gradient as a function of resistance factor. Injectivity is best defined as a function of the polymer and porous media properties, however, since they are the main factors that are included in the overall design. Li and Delshad (2014) developed an analytical model to calculate polymer injectivity while including the effect of several parameters including polymer rheology and grid size. The main limitation of the model is that it is purely analytical and is mainly developed for reservoir simulation reasons. The advantage of the model is that it removes the need to consider grid size which increases the applicability. Behr and Rafiee (2017) focused on situations where skin damage is profound in order to develop a model that can predict injectivity of polymers in this very specific case using a coarse Cartesian grid. The model has a good applicability; however, its extreme focus on cases involving skin damage limits its use. Sorbie and Roberts (1984) provided one of the earliest models for polymer injectivity which accounts for mechanical degradation. The model represents the polymer using pseudo-components which is not widely applicable and not useable in many cases. Fakher and Bai (2018) developed two mathematical models for cross-linked HPAM gel using data from multiple studies. The models could predict oil residual resistance factor as a function of polymer concentration and water residual resistance factor. The models could not predict injectivity directly, however. Fakher et al. (2017) also generated mathematical models for particle gels which could not directly predict injectivity. Hwang et al. (2019) presented an analytical model to obtain polymer injectivity for various well configurations. The model was purely analytical, however, and has multiple assumptions including an assumption for the Darcy velocity at the fracture face which is a critical component of the model. All of the previously mentioned models have several assumptions, and also, many of them are purely analytical and focus on reservoir applications with very little focus on laboratory studies and mathematical derivation.

Injectivity is measured as a function of the injection flowrate and the pressure required to inject the polymer. Since it may be difficult to obtain the exact pressure value in the field, a simple method of quantifying injectivity is needed. Reservoir simulation can be used as a means to predict the pressure requirement; however, it is not always applied and requires many inputs and in some cases long run times. Also, most of the models currently present to model polymer injectivity were developed based on core flooding rather than open conduits such as fractures. This research develops two mathematical models to predict polymer injectivity in open conduits during laboratory studies as a function of polymer concentration, polymer injection flowrate, and the porous media average pore size, all of which are parameters that are usually known during a polymer injection project. The models were developed based on experiments conducted in a previous research and were validated using data not used in the development of the models. The models were also used to predict injectivity and polymer injection pressure for different polymer injection conditions.

\section{Experimental setup}

The setup used to conduct the experiments to obtain the data used for the development of the mathematical models is shown in Fig. 1. The setup is composed of a pump used to displace all the fluids. The accumulator is filled with the polymer and then used to displace the polymer into the 


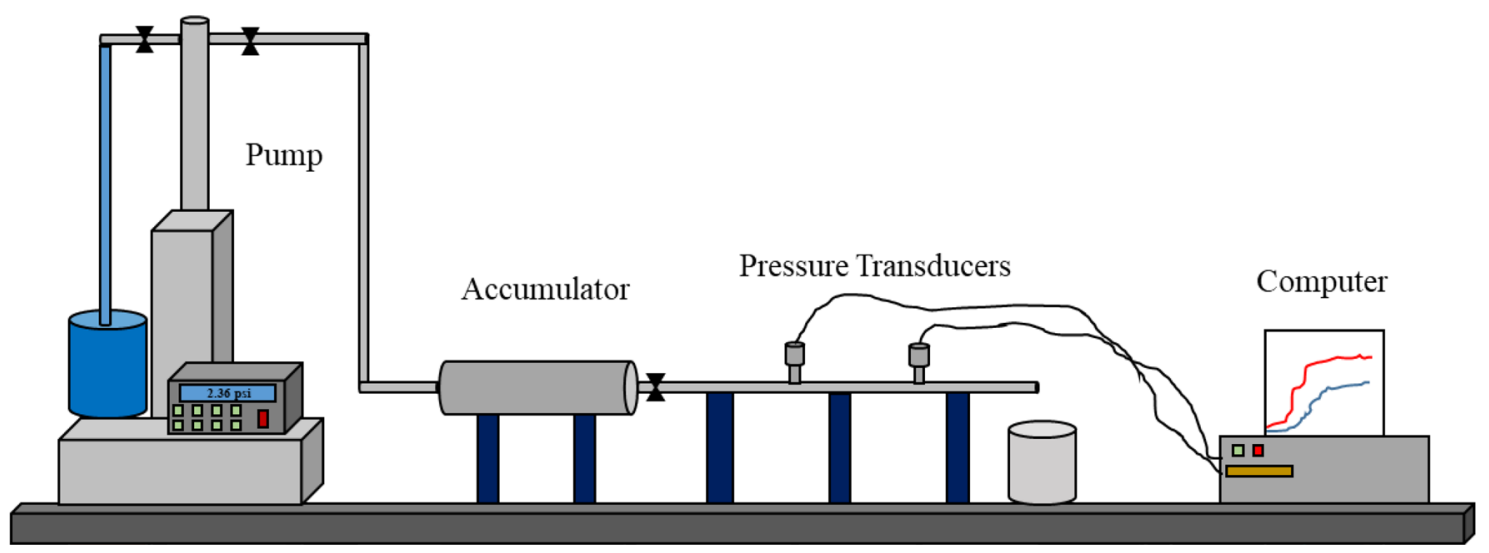

Fig. 1 Experimental setup

porous media. Tubes with different inner diameters were used to model the porous media with different pore sizes. Two pressure transducers located at the inlet and the middle of the tube were used to record the polymer injection pressure using different polymer concentrations and different polymer injection flowrates. Initially, a transducer was put at the outlet of the tube; however, the pressure reading was almost equal to zero in all cases since there was no backpressure added to the experiment. Based on this, the transducer was only put in the inlet and middle, while the outlet pressure was assumed to be $0 \mathrm{psig}$. Using the results obtained from these experiments, the mathematical models were developed. The exact procedure followed to conduct all experiments is as follows.

- Prepare the polymer solution by placing the polymer powder in the distilled water and stirring the mixture for at least $12 \mathrm{~h}$ using a magnetic stirrer. The solution should be covered during stirring to avoid any contaminants from entering the solution during the mixing process.

- Place the polymer in the accumulator and ensure that there are no air pockets between the polymers which may impact the experiments. Also, the accumulator must be fully occupied by the polymer.

- Connect the tube to the accumulator and attach the pressure transducers after they have been calibrated.

- Begin the polymer injection using the lowest flowrate. Each flowrate is stopped when the pressure becomes stable for at least two pore volumes of injection.

- Once the experiment is concluded, the accumulator and tube are cleaned and prepared for the following experiments.

\section{Mathematical model development}

The mathematical models were developed based on the experimental results obtained. Initially, a model was developed to model polymer injectivity as a function of polymer concentration and polymer injection flowrate. The models are applicable when the pore size of the porous media is relatively large to the extent that it does not create a pressure restriction; this will be mainly in extremely highpermeability features such as unconsolidated formations or continuous fractures. To increase the applicability of the model, the average pore size of the porous media was incorporated in the second model. Table 1 presents the two models and the parameters included in them along with the appropriate units for the inputs. The exact procedure followed to construct the mathematical models is as follows:

- The data from the experiments were combined and analyzed to ensure that all the data could be used for the model development.

- The data were plotted for two variables in order to determine the general trend of the data points and determine a general equation upon which the fitting can be generated.

- Based on the general equation, fitting parameter for all the related experiments was generated, and by analyzing

Table 1 Properties of mathematical models

\begin{tabular}{lll}
\hline Model name & Parameters & Parameters units \\
\hline Model I & Polymer concentration & $\mathrm{wt} \%$ \\
& Polymer injection flowrate & $\mathrm{ml} / \mathrm{min}$ \\
Model II & Polymer concentration & $\mathrm{wt} \%$ \\
& Polymer injection flowrate & $\mathrm{ml} / \mathrm{min}$ \\
& Porous media average pore size & inch \\
\hline
\end{tabular}


the trendline for each experiment, the values of the fitting parameters were determined.

- Using the fitting parameters, a general equation was developed that incorporated the data from all the experiments involved by combining all the fitting parameters for each experiment into one mathematical model.

Model validation used the data included in the model developed and also data not included in the model development in order to assess the applicability of foreign data to the models. All data used were for the same HPAM polymer used to conduct the experiments.

\section{Results and analysis}

This section will include the mathematical models' development and their usage to predict polymer injectivity and polymer injection pressure. The limitations of the models will also be mentioned.

\section{Mathematical Model I}

Injectivity is defined mathematically as the ratio between polymer injection flowrate and polymer injection pressure, as is shown in Eq. (1).

$I_{\mathrm{p}}=\frac{Q}{\Delta P}$

where $I_{\mathrm{p}}$ is the polymer injectivity, $Q$ is the polymer injection flowrate, and $\Delta P$ is the difference between the polymer injection pressure and the outlet pressure.
After conducting the experiments, the polymer injection pressure was determined, and hence, the injectivity was calculated. Figure 2 shows the polymer injectivity results at different polymer injection flowrates for different polymer concentrations for the $1 / 16$ and $1 / 8$ inch inner diameters. The results were used in the development of both mathematical models.

For each trend in Fig. 2, an equation was obtained. It was found that all the equations followed the general form of the power model. A general equation was therefore defined as follows, Eq. (2).

$I_{\mathrm{p}}=a Q^{b}$.

where " $a$ " and " $b$ " are constants that represent the values obtained from each equation for the different parameters. Parameters " $a$ " and " $b$ " are fitting parameters that are used to generalize a variable of different values into one mathematical model. On their own, they have no physical

Table 2 " $a$ " and " $b$ " parameters values for all trendlines

\begin{tabular}{lllll}
\hline $\begin{array}{l}\text { Polymer concen- } \\
\text { tration wt } \%\end{array}$ & Pore size inch & $a$ & $b$ & $R^{2}$ \\
\hline 0.1 & 0.0625 & 3.0775 & 0.343 & 0.936 \\
0.5 & 0.0625 & 0.4398 & 0.6478 & 0.9817 \\
1 & 0.0625 & 0.2186 & 0.7461 & 0.9776 \\
2 & 0.0625 & 0.0752 & 0.8163 & 0.9953 \\
0.1 & 0.125 & 8.425 & 0.712 & 0.995 \\
0.5 & 0.125 & 1.7254 & 0.8279 & 0.9979 \\
1 & 0.125 & 0.6176 & 0.9029 & 0.9982 \\
2 & 0.125 & 0.2595 & 0.909 & 0.9988 \\
\hline
\end{tabular}

$\bullet 0.1 \mathrm{wt} \%$ Polymer $\backsim 0.5 \mathrm{wt} \%$ Polymer $\Delta 1 \mathrm{wt} \%$ Polymer $\bullet 2 \mathrm{wt} \%$ Polymer
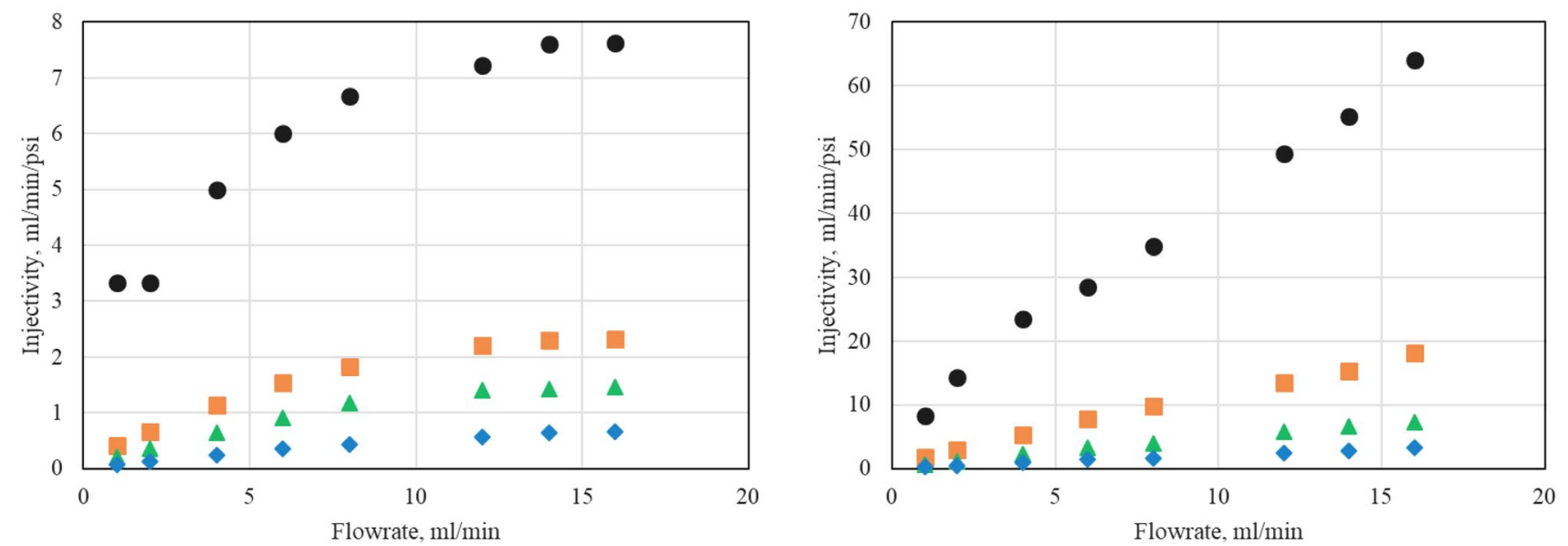

Fig. 2 Polymer injectivity at different flowrates for the a 1/16 inch and b 1/8 inch ID 
meaning. They are related to the variable from which they were developed.

The values of the " $a$ " and " $b$ " parameters for each equation are presented in Table 2. The $R^{2}$ value for each of the equations is also presented; $R^{2}$ is a measure of the accuracy of the developed equation, with a maximum value of 1 for the highest accuracy and a minimum value of 0 for the lowest accuracy. The accuracy of the trendlines obtained was found to be extremely high, with all of the values greater than $95 \%$, which is an indication of the accuracy of the experiments conducted.

The general form of the equation, presented in Eq. (2), was a function of both " $a$ " and " $b$." In order to obtain a mathematical model as a function of polymer concentration, the " $a$ " and " $b$ " parameters were plotted against the polymer concentration, and an equation was obtained to relate " $a$ " and " $b$ " to the polymer concentration. Figure 3 shows the plots for " $a$ " and " $b$ " parameters with polymer concentration, along with the correlations obtained. The blue line represents " $a$ " parameter, while the green line represents " $b$ " parameter.

Using the equations generated in Fig. 3, and plugging the values in Eq. (2), the following equations were obtained for polymer injectivity. Equation (3) was developed for the 1/16 inch average pore size, while Eq. (4) was developed for the $1 / 8$ inch average pore size.

$I_{\mathrm{p}}=0.1918 C_{\mathrm{p}}^{-1.216} Q^{0.7201 C_{\mathrm{p}}^{0.2983}}$

$I_{\mathrm{p}}=0.6332 C_{\mathrm{p}}^{-1.161} Q^{0.8768 C_{\mathrm{p}}^{0.0869}}$

where $I_{\mathrm{p}}$ is the polymer injectivity in $\mathrm{ml} / \mathrm{min} / \mathrm{psi}, C_{\mathrm{p}}$ is the polymer concentration, and $Q$ is the polymer injection flowrate.

The most major disadvantage of Model I is that it is not a function of the average pore size of the formation. This limits its applicability greatly. Equation (4) was tested for larger pore sizes and was found to predict injectivity with considerable accuracy; however, the deviation from the true solution was still considered too high. It was therefore important to incorporate the pore size in the mathematical model, to increase the applicability of the developed models. Model I was mentioned in order to provide the general methodology by which the mathematical models were generated, and also since the tube sizes of 1/16 and 1/8 inch are extremely common for laboratory experiments, Model I can still prove valuable for laboratory applications using these two pore sizes.

\section{Mathematical Model II}

In order to incorporate a third variable in the mathematical model, a new parameter was defined. The parameter is a ratio between the polymer concentration and polymer injection flowrate. Table 3 shows the values for this parameter.

By defining the new parameter, three variables could be incorporated in one plot. The polymer injectivity and the $C p / Q$ parameter were plotted together for different pore sizes, shown in Fig. 4, and the correlations that fit the data points were generated. From the two correlations generated, the " $a$ " and " $b$ " parameters could be obtained. A zoom-in on the majority of the data points is also provided in Fig. 4 in the right-hand plot.

The " $a$ " and " $b$ " parameters were plotted as a function of the average porous media pore size in order to relate both parameters. Figure 5 shows the relation between " $a$ " and " $b$ " and pore size; the blue line represents the " $a$ " parameter, while the green line represents the " $b$ " parameter. The " $b$ " parameter values were plotted as absolute values, and then, the negative sign was added in the final mathematical model.

Using the correlations obtained from Fig. 5, and the general correlation, shown in Eq. (2), Model II was developed and is shown in Eq. (5).
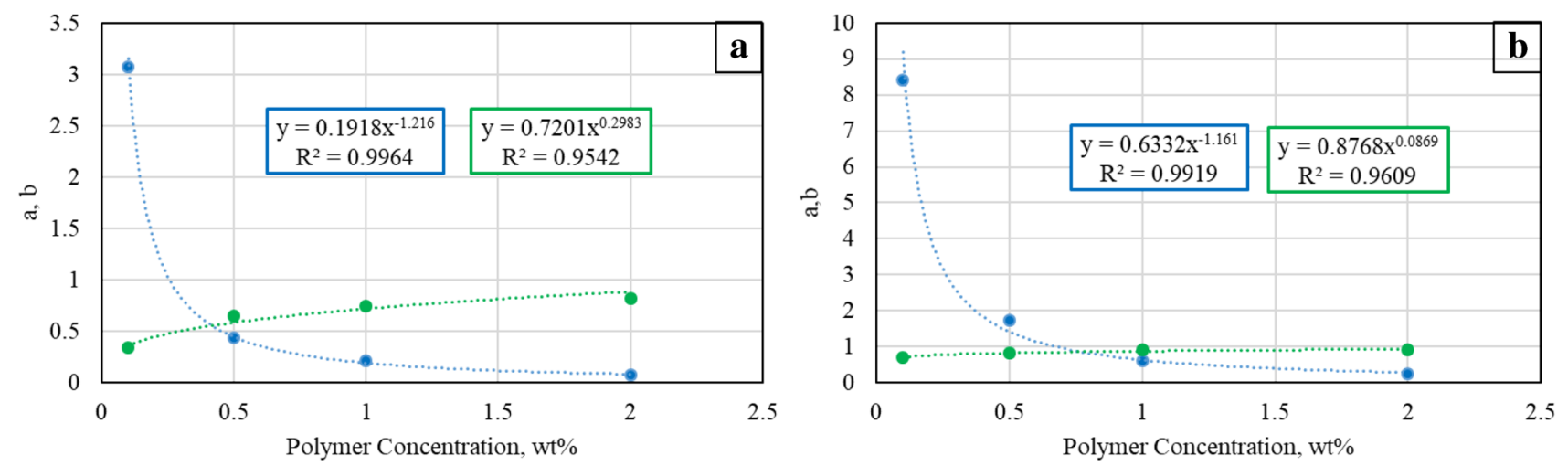

Fig. 3 a and $\mathbf{b}$ coefficients for $\mathbf{a} 1 / 16$ inch $\mathbf{b} 1 / 8$ inch ID 
Table 3 Values of $\mathrm{Cp} / \mathrm{Q}$ parameter at different pore sizes

\begin{tabular}{llllll}
\hline Tube size inch & $\begin{array}{l}\text { Injectivity, } \mathrm{ml} / \\
\mathrm{min} / \mathrm{psi}\end{array}$ & $\mathrm{Cp} / \mathrm{Q}, \mathrm{min} / \mathrm{ml}$ & Tube size, inch & $\begin{array}{l}\text { Injectivity, } \mathrm{ml} / \\
\mathrm{min} / \mathrm{psi}\end{array}$ & $\mathrm{Cp} / \mathrm{Q}, \mathrm{min} / \mathrm{ml}$ \\
\hline $1 / 16$ & 7.619 & 0.00625 & $1 / 8$ & 64 & 0.00625 \\
& 6.667 & 0.0125 & & 34.783 & 0.0125 \\
5 & 0.025 & 23.53 & 0.025 \\
2.318 & 0.03125 & 18.182 & 0.03125 \\
1.819 & 0.0625 & 9.756 & 0.0625 \\
& 3.333 & 0.1 & 8.333 & 0.1 \\
1.15 & 0.125 & 5.333 & 0.125 \\
& 9.645 & 0.25 & 2.247 & 0.25 \\
& 0.4167 & 0.5 & 1.818 & 0.5 \\
0.204 & 1 & 0.592 & 1 \\
& 0.0725 & 2 & 0.251 & 2 \\
\hline
\end{tabular}

0.0625 inch ID $\bullet 0.125$ inch ID

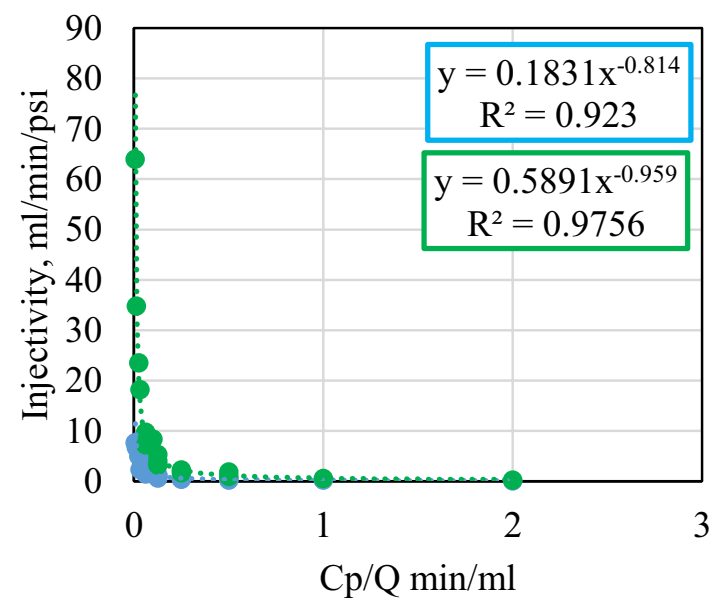

$\bullet 0.0625$ inch ID $\bullet 0.125$ inch ID

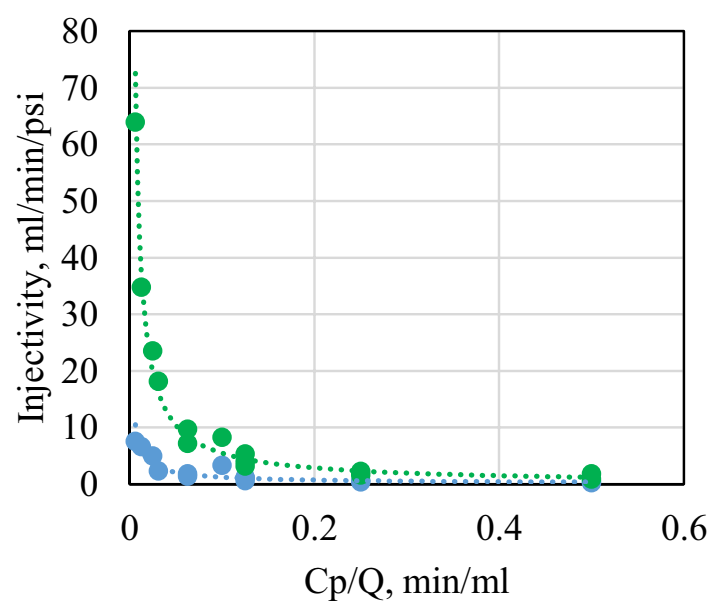

Fig. 4 Polymer injectivity as a function of polymer concentration and injection flowrate

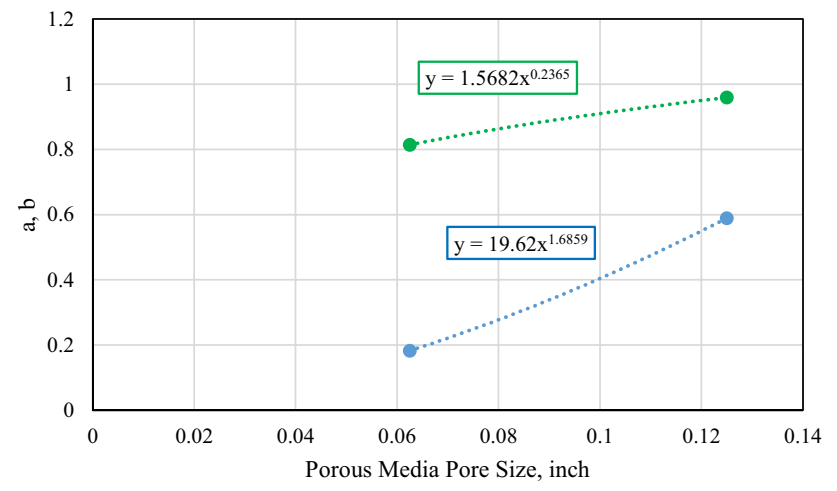

Fig. 5 "a" and "b" parameters for different pore sizes
$I_{\mathrm{p}}=19.62 T_{\mathrm{s}}^{1.6859}\left(\frac{C_{\mathrm{p}}}{Q}\right)^{-1.5682 T_{\mathrm{s}}^{0.2365}}$

where $I_{\mathrm{p}}$ is the polymer injectivity in $\mathrm{ml} / \mathrm{min} / \mathrm{psi}, T_{\mathrm{s}}$ is the average porous media pore size in inch, $C_{\mathrm{p}}$ is the polymer concentration in wt $\%$, and $Q$ is the polymer injection flowrate in $\mathrm{ml} / \mathrm{min}$.

Model II was developed as a function of three different parameters and thus has an extremely high applicability range, compared to Model I. Model II will therefore be used for prediction of injectivity under different conditions.

\section{Model II prediction}

Model II was used to predict the polymer injectivity value for different polymer concentrations, different polymer injection flowrates, and different pore sizes. The results for the polymer 


\section{$\Delta 5 \mathrm{ml} / \mathrm{min} \quad 10 \mathrm{ml} / \mathrm{min} \bullet 50 \mathrm{ml} / \mathrm{min}$}
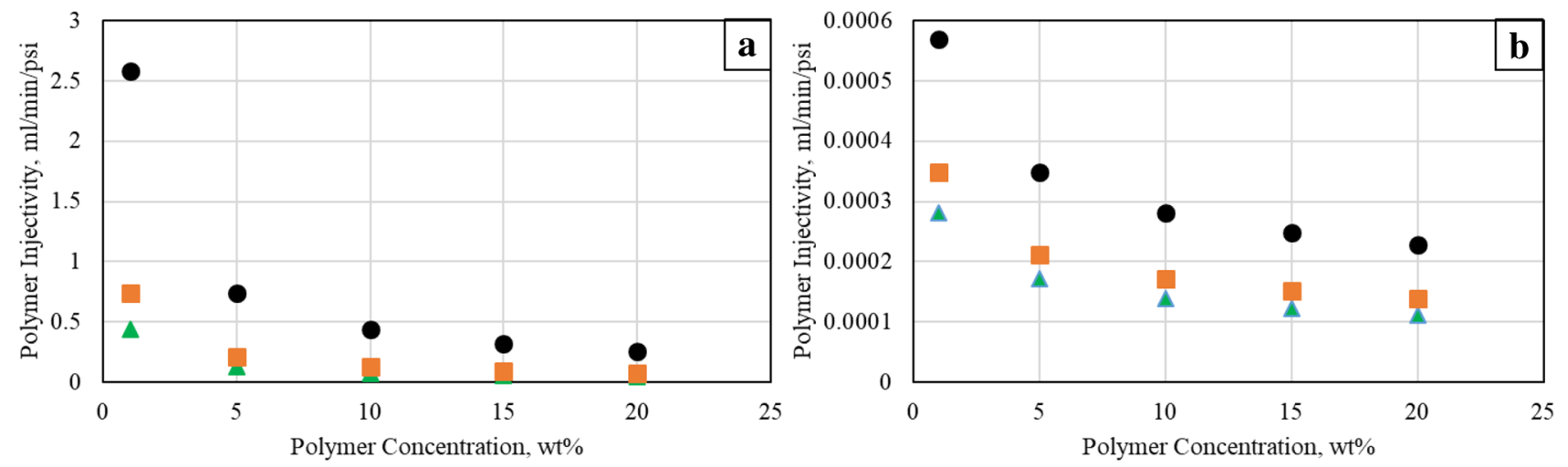

Fig. 6 Predicted polymer injectivity using a 0.05 and b 0.001 inch pore size

injectivity are presented in Fig. 6. All the values used were different from those used in the polymer injection experiments in order to investigate the ability of the mathematical mode to predict injectivity using different values. The trend observed follows the same trend found from the experiments and from other researches (Al-Shakry et al. 2018, 2019; Yerramilli et al. 2013; Lotfollahi et al. 2016; Seright et al. 2009). Increasing the polymer concentration resulted in a decrease in injectivity, while increasing the flowrate increased the injectivity value. The smaller pore size resulted in extremely low injectivity values, thus indicating that the polymer will be very difficult to inject in the 0.001 inch pore size.

Since injectivity is a function of both polymer injection flowrate and polymer injection pressure, the polymer injection pressure can be predicted if the injectivity and the injection flowrates are known. Figure 7 presents the predicted polymer injection pressures for different conditions of polymer injection using Model II. After the injectivity was known, the polymer injection flowrate was divided by the injectivity value to obtain the polymer injection pressure. Model II can therefore help in predicting both polymer injectivity and polymer injection pressures, both of which are extremely important parameters during any polymer injection project.

\section{Mathematical model limitations}

The developed mathematical models have several limitations that should be mentioned. These include:

- The models were developed for large features in the reservoir and thus may not be applicable for core flooding experiments. They are rather meant for larger features such as unconsolidated formations or fractures.

- HPAM is available in a wide range of forms and through many distributors, and also has different degrees of hydrolysis. The model has not been tested for a variety of HPAM types.
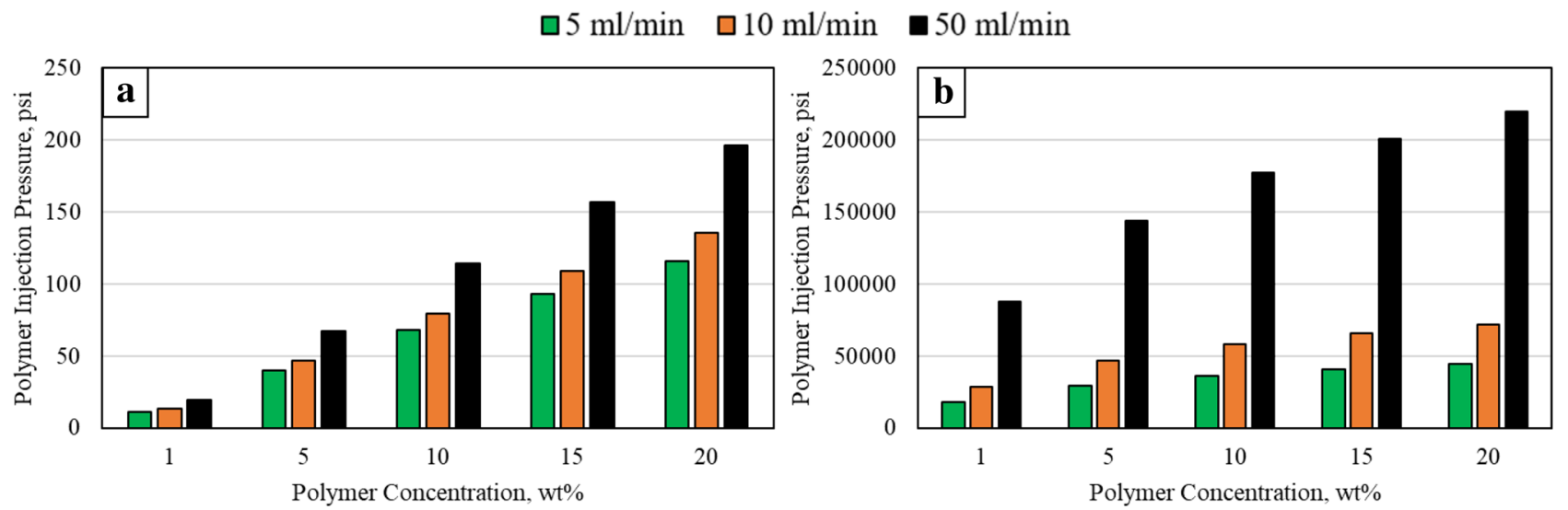

Fig. 7 Predicted polymer injection pressure using $\mathbf{a} 0.05$ and $\mathbf{b} 0.001$ inch pore size 
- The model predicts injectivity as a single value by assuming an average pore size for the formation, which is not necessarily true in many formations since it does not take into consideration tortuosity or change in pore size.

- The model has not been tested for different polymers and is thus only applicable for HPAM.

- The models were developed based on HPAM mixed with distilled water. Their applicability with HPAM in brine was not assessed.

- The models were developed using pores sizes of $1 / 8$ and $1 / 16$ inches only and thus should be applied for these sizes accordingly.

\section{Conclusions}

This research develops two mathematical models to predict HPAM injectivity as a function of polymer concentration, polymer injection flowrate, and porous media pore size during laboratory studies. The developed model was found to accurately predict HPAM injectivity with a very low percentage error. The model could also be used to determine the injection pressure requirement for different HPAM designs, and also give an indication of whether the polymer can be injected into the reservoir average pore size based on the pressure requirements. By developing these mathematical models, HPAM injectivity can be predicted based on the polymer design in order to determine whether the polymer will be able to propagate through high-permeability features in the reservoir easily and safely.

Acknowledgements The author wishes to thank Missouri University of Science and Technology for its support through the Chancellor's Distinguished Fellowship.

\section{Compliance with ethical standards}

Conflict of interest The authors declare that they have no conflict of interest.

Open Access This article is licensed under a Creative Commons Attribution 4.0 International License, which permits use, sharing, adaptation, distribution and reproduction in any medium or format, as long as you give appropriate credit to the original author(s) and the source, provide a link to the Creative Commons licence, and indicate if changes were made. The images or other third party material in this article are included in the article's Creative Commons licence, unless indicated otherwise in a credit line to the material. If material is not included in the article's Creative Commons licence and your intended use is not permitted by statutory regulation or exceeds the permitted use, you will need to obtain permission directly from the copyright holder. To view a copy of this licence, visit http://creativecommons.org/licenses/by/4.0/.

\section{References}

Al-Shakry B, Shiran BS, Skauge T, Skauge A (2018) Enhanced oil recovery by polymer flooding: optimizing polymer injectivity. Soc Pet Eng. https://doi.org/10.2118/192437-MS

Al-Shakry B, Shaker Shiran B, Skauge T, Skauge A (2019) Polymer injectivity: influence of permeability in the flow of EOR polymers in porous media. Soc Pet Eng. https://doi.org/10.2118/195495-MS

Baijal SK (1975) Interaction during polymer flooding. Soc Pet Eng. https://www.onepetro.org/general/SPE-5849-MS

Behr A, Rafiee M (2017) Prediction of polymer injectivity in damaged wellbore by using rheological dependent skin. Soc Pet Eng. https ://doi.org/10.2118/186054-MS

Bryant SL et al (1998) Experimental investigation on the injectivity of phenol-formaldehyde/polymer gels. Soc Pet Eng. https://doi. org/10.2118/52980-PA

Buell RS et al (1990) Analyzing injectivity of polymer solutions with the hall plot. Soc Pet Eng. https://doi.org/10.2118/16963-PA

De Simoni M et al (2018) Polymer injectivity analysis and subsurface polymer behavior evaluation. Soc Pet Eng. https://doi. org/10.2118/190383-MS

Delamaide E (2019) How to use analytical tools to forecast injectivity in polymer floods. Soc Pet Eng. https://doi.org/10.2118/19551 3-MS

Delamaide E, Zaitoun A, Renard G, Tabary R (2014) Pelican lake field: first successful application of polymer flooding in a heavy-oil reservoir. Soc Pet Eng. https://doi.org/10.2118/165234-PA

Erincik MZ, Qi P, Balhoff MT, Pope GA (2018) New method to reduce residual oil saturation by polymer flooding. Soc Pet Eng. https:// doi.org/10.2118/187230-PA

Fakher S (2019a) Investigating factors that may impact the success of carbon dioxide enhanced oil recovery in shale reservoirs. Soc Pet Eng. https://doi.org/10.2118/199781-STU

Fakher SM (2019b) Asphaltene stability in crude oil during carbon dioxide injection and its impact on oil recovery: a review, data analysis, and experimental study. Masters Theses. 7881

Fakher S, Bai B (2018) A newly developed mathematical model to predict hydrolyzed polyacrylamide crosslinked polymer gel plugging efficiency in fractures and high permeability features. Soc Pet Eng. https://doi.org/10.2118/191180-MS

Fakher S, Imqam A (2018) Investigating and mitigating asphaltene precipitation and deposition in low permeability oil reservoirs during carbon dioxide flooding to increase oil recovery. Soc Pet Eng. https://doi.org/10.2118/192558-MS

Fakher S, Imqam A (2020a) A data analysis of immiscible carbon dioxide injection applications for enhanced oil recovery based on an updated database. https://doi.org/10.1007/s42452-020-2242-1

Fakher S, Imqam A (2020b) Application of carbon dioxide injection in shale oil reservoirs for increasing oil recovery and carbon dioxide storage. Fuel. https://doi.org/10.1016/j.fuel.2019.116944

Fakher S et al (2017) Novel mathematical models to predict preformed particle gel placement and propagation through fractures. Soc Pet Eng. https://doi.org/10.2118/187152-MS

Fakher $S$ et al (2018) Investigating the viscosity reduction of ultraheavy crude oil using hydrocarbon soluble low molecular weight compounds to improve oil production and transportation. Soc Pet Eng. https://doi.org/10.2118/193677-MS

Fletcher A et al (1992) Formation damage from polymer solutions: factors governing injectivity. Soc Pet Eng. https://doi. org/10.2118/20243-PA

Gerlach B et al (2019) Best surfactant for EOR polymer injectivity. Soc Pet Eng. https://doi.org/10.2118/198097-MS

Glasbergen $G$ et al (2015) Injectivity loss in polymer floods: causes, preventions and mitigations. Soc Pet Eng. https://doi. org/10.2118/175383-MS 
Hwang J et al (2019) Viscoelastic polymer injectivity: a novel semianalytical simulation approach and impact of induced fractures and horizontal wells. Soc Pet Eng. https://doi.org/10.2118/19597 8-MS

Juri JE et al (2015) Estimation of polymer retention from extended injectivity test. Soc Pet Eng. https://doi.org/10.2118/174627-MS

Koh H, Lee VB, Pope GA (2018) Experimental investigation of the effect of polymers on residual oil saturation. Soc Pet Eng. https:// doi.org/10.2118/179683-PA

Li Z, Delshad M (2014) Development of an analytical injectivity model for non-newtonian polymer solutions. Soc Pet Eng. https://doi. org/10.2118/163672-PA

Lotfollahi M, Farajzadeh R, Delshad M, Al-Abri A-K, Wassing BM, Al-Mjeni R, Bedrikovetsky P (2016) Mechanistic simulation of polymer injectivity in field tests. Soc Pet Eng. https://doi. org/10.2118/174665-PA

Manichand RN, Moe Soe Let KP, Gil L, Quillien B, Seright RS (2013) Effective propagation of HPAM solutions through the tambaredjo reservoir during a polymer flood. Soc Pet Eng. https ://doi.org/10.2118/164121-PA

Schmidt J et al (2019) Novel method for mitigating injectivity issues during polymer flooding at high salinity conditions. Soc Pet Eng. https://doi.org/10.2118/195454-MS

Seright RS (2017) How much polymer should be injected during a polymer flood? Review of previous and current practices. Soc Pet Eng. https://doi.org/10.2118/179543-PA

Seright RS, Seheult JM, Talashek T (2009) Injectivity characteristics of EOR polymers. Soc Pet Eng. https://doi.org/10.2118/115142-PA

Seright RS, Wang D, Lerner N, Nguyen A, Sabid J, Tochor R (2018) Can 25-cp polymer solution efficiently displace 1600-cp oil during polymer flooding? Soc Pet Eng. https://doi.org/10.2118/19032 1-PA
Sharma KK et al (2016) Polymer injectivity test in Bhagyam field: planning, execution and data analysis. Soc Pet Eng. https://doi. org/10.2118/179821-MS

Shuler PJ, Kuehne DL, Uhl JT, Walkup GW (1987) Improving polymer injectivity at west coyote field. Soc Pet Eng, California. https:// doi.org/10.2118/13603-PA

Skauge T et al (2016) Radial and linear polymer flow-influence on injectivity. Soc Pet Eng. https://doi.org/10.2118/179694-MS

Smith FW (1970) The behavior of partially hydrolyzed polyacrylamide solutions in porous media. Soc Pet Eng. https://doi. org/10.2118/2422-PA

Sorbie KS, Roberts LJ (1984) A model for calculating polymer injectivity including the effects of shear degradation. Soc Pet Eng. https ://doi.org/10.2118/12654-MS

Southwick JG, Manke CW (1988) Molecular degradation, injectivity, and elastic properties of polymer solutions. Soc Pet Eng. https:// doi.org/10.2118/15652-PA

Weiss WW, Baldwin RW (1985) Planning and implementing a largescale polymer flood. Soc Pet Eng. https://doi.org/10.2118/12637 -PA

Yerramilli SS, Zitha PLJ, Yerramilli RC (2013) Novel insight into polymer injectivity for polymer flooding. Soc Pet Eng. https:// doi.org/10.2118/165195-MS

Zhou Y, Muggeridge AH, Berg CF, King PR (2019) Effect of layering on incremental oil recovery from tertiary polymer flooding. Soc Pet Eng. https://doi.org/10.2118/194492-PA

Publisher's Note Springer Nature remains neutral with regard to jurisdictional claims in published maps and institutional affiliations. 